\title{
Cross-cultural Communication- How Does Japanese Animation Adapt American Cultural Values to Satisfy American Consumers?
}

\author{
Qijia Zhou ${ }^{1 *}$ Yisui Tang ${ }^{2}$
}

\author{
${ }^{1}$ Bond International College, Toronto, MIP 2G5, Canada \\ ${ }^{2}$ School of Social Science, Michigan State University, East Lansing, MI 48824, the United States of America \\ *Corresponding author. Email: alfred030703@gmail.com
}

\begin{abstract}
In the context of business communication, the topic of cross-cultural adaptation is often discussed. This research report is committed to discuss the differences in ways American and Japanese audiences interpret animation series and the reason why Japanese anime could become successful in the United States. By combining both theoretical research and a practical example, it was possible to conclude factors for organizations to consider when entering a foreign market, such as constructing local authenticity and adapting crucial cultural values. The most significant discovery, however, is to identify outstanding elements that appeal to a certain group of audiences.
\end{abstract}

Keywords: storytelling, trigon, heroism.

\section{INTRODUCTION}

Japanese animation, also known as "anime", is handdrawn and computer animation exclusively originated from Japan. Over approximately twenty years in the 1970s and 1980s, anime gained recognition in the United States. American anime streaming sites such as Crunchyroll now have over 70 million registered users and over 3 million paid subscribers [1]. Japanese anime has prospered among its American consumers. Interestingly, Japan and the United States are known for their cultural differences, such as their gratitude and apologies. In fact, there is an exceedingly large number of cultural differences in almost every aspect [2]. More importantly, anime is a Japanese cultural-media product that was not originally designed for the American market [3]. Still, it seems to be appealing to American viewers who are culturally unlike. Thus, it is worth assessing how Japanese anime adapt some of the American cultural values to ensure acceptance from its American viewers.

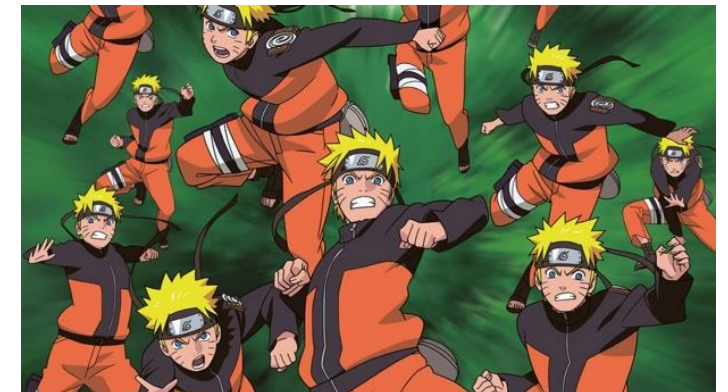

Figure.1 Naruto Shippuden, Masashi Kishimoto [20]

According to Nguyen-Phuong-Mai, companies need to navigate products through local culture complexity and adapt consumers' behaviors in the cross-cultural communication context. Certain products that stimulate customers from the same culture might not be effective for those from another culture [4]. Thus, it is requisite to investigate cultural factors such as independence, interpersonal relationship, social opinion, hierarchy, and social interaction. This research report will discuss the adaptation of individualism and storytelling elements of Japanese anime in the United States, then applying the findings to a well-recognized anime series. 


\section{BACKGROUND AND CULTURAL DIFFERENCES}

\subsection{Anime: Current Situation}

The conflict of values has always been a barrier to the communication between cultures. However, there is a shared identity carrier to connect the contact. The word animation is not just a cartoon on TV but includes the entire transportation of using images to interpret the story, including comics or comic strips, and influences Japanese society, including culture, history, religion and so on [5]. Japanese animation has become one of the most popular media for storytelling [6]. At the same time, Japanese comics are more popular among American teenagers and became a new culture. By 2003, 60\% of global broadcast animation was Japanese animation [7]. Sean Atkins, a creative director of online programs, mentioned that at least $40 \%$ of online programs in America are inspired by Japanese animation [8].

\subsection{Individualism vs. Collectivism}

Japanese are euphemistic, cautious, and humble. They will take care of the conception of audiences more, but it is often considered as a negative attitude. Most of the time, Americans seem to be more confident because the American "pioneer history" has cultivated enough positive attitudes. When working together, the Japanese advocate that all members should do one thing together in one group; they will subconsciously agree with other people's opinions, even if they hold the opposite attitude. On the contrary, it is relatively normal for Americans to think that everyone is different from others, so it is imperative to express one's opinions directly if they want to be comprehended by others.

\subsection{Difference of Preference in Storytelling}

McCloud proposed that animation has become a popular culture because it has the characteristics of audience identification, and the audience's identification with the story characters can affect the audience's investment [9]. Until now, Japanese comics still use aspect-to-aspect transitions to convey information, and this is a part that cannot be ignored from the beginning. Japanese comic writers use aspect-to-aspect transformation to build an emotional or spatial sense, giving audiences full scope of imagination.

At first, comics told stories in serial pictures and were called "serial art" [10]. In the 12th century, a new form of comic serial drama, Kamishibai, also known as paper drama, appeared on the streets of Japan. Kamishibai became popular in the 1930s and was eventually replaced by television (Rob Fisher, 2019). Performers usually perform on the road, using illustrated boards placed in a small tool to tell stories [11]. From the perspective of
Japanese narrative tradition, Japanese comics and animation are likely evolved from Kamishibai.

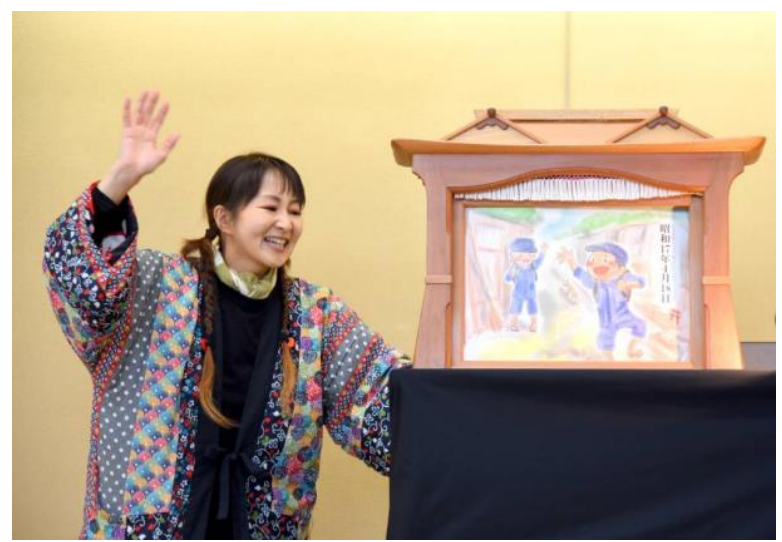

Figure.2 Japanese Kamishibai, Sakoto Kawasaki [21]

A classic Japanese story of Kamishibai, three magic charms, tells that "A priest finds chestnuts on a mountain and then meets an old woman. She said she was his relative and told him that she would cook chestnuts at home." [12].

Waller, an American, once told the same story: "once upon a time, there was a little boy who was studying with an old monk every day. He had never met anyone before, but he met an old lady one afternoon when he was waking. She greets him kindly and invites the little boy to have dinner with her. The little boy was confused, but he still accepted it." [13]

More importantly, the American story is more detailed than the Japanese story, which is related to the culture of the two countries. More obscure, less information, leaving the audience more imagination space, and hoping that the audience can understand the answers they want; the American story will be more direct and obvious, will tell the audience the cause and result of the event directly, because they want to be able to shape the hero or bad character clearly.

\section{AN UNDENIABLE ATTRACTION: THE CASE OF TRIGUN APPLYING AMERICAN CULTURAL ELEMENTS}

Because of the enormous gap between Japanese and American cultural values, there is certainly a significant difference in audiences' ways of interpreting content. Different audiences construe anime at variance, which is a strategy that companies can implement for more acceptable cognizance among American audiences. In 1998, the Japanese anime series "Trigun" was imported to the American market and obtained success in building its audience base. However, the series disappointed the Japanese audiences, who did not find Trigun appealing. Its main character, Vash the Stampede, especially received critical reviews while being one of the most popular anime characters in the United States. Kasa also suggested in the thesis that "Trigun contains elements 
that American viewers immediately recognize, resonate with and foreground, elements that have no special significance for the Japanese viewer......American viewers seek out and foreground those elements of Trigun that resemble the American western genre" [14]. To summarize, the American audiences must have acknowledged elements that they can make explicit meanings in Trigun. To develop and assess Trigun's attractions to the American viewers, it is essential to analyze the structural American cultural elements, including individualism and storytelling elements involved in the audience reception of Trigun among the American audiences.

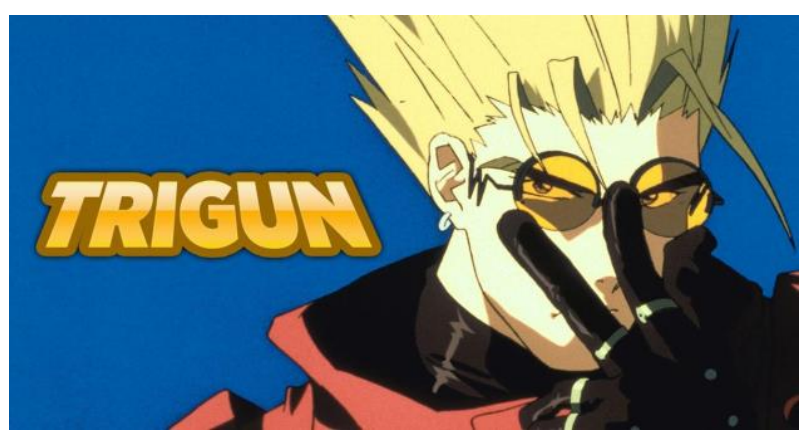

Figure. 3 Trigun, Madhouse Studio [22]

\subsection{Guns: self-defence or violence?}

Over the past few decades, carrying and using firearms have been a controversial topic. As two countries with contrasting cultural values, Japan and the United States undoubtedly have two incompatible approaches to weapons. Vividly, a gun is the representation of justification and corresponding construction of masculinity, according to Joyce [15]. More importantly, gun enthusiasm to the Americans demonstrates them valuing American history and believing in the values associated with American patriotism. Mainly, cowboy action shooters are the western culture that values gun violence to claim their identity as authentic American citizens [16]. Generally, the Americans, who appreciate individualism, view guns as tools to secure self-defense and claim cultural authenticity.

The Japanese, on the other hand, cling to the belief that guns impact society more negatively. According to Morillo, as a progressive country, Japan believes that a more robust government is the critical force behind the revolution and construction of the country, not the introduction of guns [17]. As a country that values collectivism, Japan's approach to guns is implementing control over firearms to achieve more excellent social stability. According to GunPolicy.org, only nine deaths were resulting from firearms in 2018. In comparison, 39,740 people died from gun violence in 2018 , which is $4,000 \%$ times more than cases in Japan [18]. Generally, the United States is at variance with Japan on the use of firearms, which is why Trigun did not receive appreciation in Japan. Under this premise, it is a necessity to assess how Trigun adapted to American gun culture.

The setting of Trigun is majorly mixed with Western genre elements. The story takes place on a desert planet in the future, where humans must rely on gigantic energy plants to generate any electricity. With the lack of electricity and natural resources, citizens in sovereign states often combat for survival. Those with firearms automatically have the competitive advantage to compete for resources. Notably, it expedites criminals and bounty hunters who are the most significant hostilities on the desert planet with the most access to resources. More importantly, massive-scale shooting happens daily on the desert planet. Citizens use guns to protect themselves from being robbed. Out-laws regard guns as a tool to obtain resources. According to Joyce, guns are significant to Americans not only because they can be used violently but it is also because of the necessity of self-defense as an individual right [15]. By applying Joyce's statement to the settings of Trigun, it is effortless to connect the importance of guns to the Americans as an element that appealed to them, which influenced their orientation of receiving the story. An individualism-cringed firearm use attracts the American audiences while disturbing the Japanese.

\subsection{Storytelling: hero or villain?}

Similar to its storytelling elements, the Japanese value indirection and ambiguity for human relationships prevail. They tend not to speak directly and straightforwardly when discussing personal relationships, which they regard as beneficial for their business advancement [19]. This value is reflected in the storytelling style specifically, as the stories usually leave space for the audiences to develop the characters themselves independently. On the other hand, Americans likely value straightforwardness, as evidenced by their tendency to be logical and honest. It is a significant contrast to the supposed Japanese style of indirection and subtlety [19]. With this in mind, the storytelling style in the series Trigun should be assessed to identify the reason for its success in the United States.

Remarkably, the settings and character backgrounds are provided to the audience in the first five episodes of Trigun, and the main characters are mostly presented in front of the audiences. The protagonist, Vash the Stampede, is notorious for having billions of bounties on his head. However, he is compassionate, caring, and is a man of principle. His bounties originated from environmental damage he accidentally caused, not from murdering nor robbery like the most wanted do. He only fires his gun when someone needs to be saved from emergencies such as encountering out-laws. 


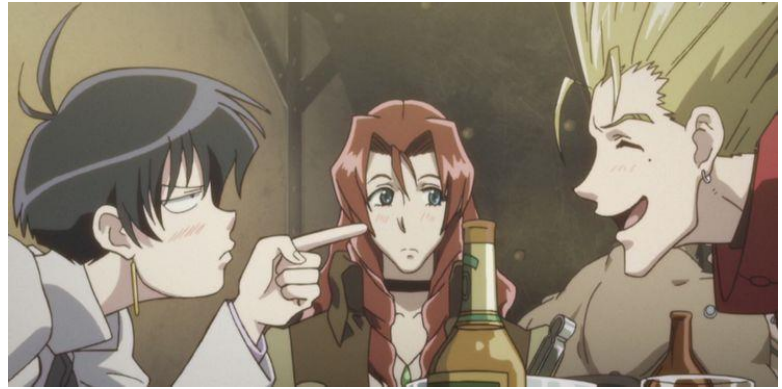

Figure. 4 Vash the Stampede, right 1, Madhouse [23]

Most importantly, he never kills, not even his enemies who attempted to murder him. The settings provided initially are obvious: Vash the Stampede is a hero with moral standards. He values lives, peace, and balance. He is accompanied by two insurance agencies who intend to reduce the damage he causes as limited as possible. Yet, they found out the truthful heroism in Vash in the fifth episode when he fired a gun to protect citizens. In summary, the character's backgrounds and intentions were delivered to maximize the American audiences' reception of this modified Western genre anime.

\section{CONCLUSION}

The case of Trigun proves the significance of adapting cross-cultural values when promoting media products. The vital aspect of the adaptation process is to identify appealing elements and to render authenticity. According to Kasa (2003), "American fans saw Trigun as another variation on, or an expansion of, the western genre, reinterpreting Trigun as something American, not as a Japanese attempt to be American." Trigun was successful at constructing authenticity and changing its Japanese values to attract American viewers. Based on the conclusions presented, the following recommendations are suggested for organizations that wish to conduct media streaming businesses internationally:

1. When promoting media products to a crosscultural audience, companies must recognize the preference of either individualism or collectivism of a particular group to connect products to audiences' expectations. The use of words, settings, and characters need to be adjusted based on such preferences.

2. The method of narrating the media products must be adjusted to fit local audiences' interests and conventions (direct vs. indirect). Use of words, slangs, and certain cultural elements should be considered with respect to whether local audiences feel comfortable or not.

3. When approaching a cross-cultural market with a significant cultural gap, companies must analyze the cultural symbols before designing media products to allow general acceptance among local audiences.

\section{REFERENCES}

[1] Coats, C. (2020). Crunchyroll Crosses Three Million Subscribers! Crunchyroll. https://www.crunchyroll.com/animenews/2020/07/28/crunchyroll-crosses-threemillion-subscribers

[2] Lee, H., Park, H., Imai, T., \& Dolan, D. (2012). Cultural Differences Between Japan and the United States in Uses of "Apology" and "Thank You" in Favor Asking Messages. Journal of Language and Social Psychology, 31(3), 263-289.

[3] Hernández-Pérez, Manuel. "Otaku Tourists Out of Japan: Fictionality, Shared Memories, and the Role of National Branding in the Japanese Pilgrimages of Anime Fans in the United Kingdom." Journal of Popular Culture, vol. 52, no. 6, WILEY, 2019, pp. 1512-35, doi:10.1111/jpcu.12871..

[4] Nguyen-Phuong-Mai, M. (2020). Cross-Cultural Management (1st ed., Vol. 1, pp.293-323). Routledge.

[5] Frasier, A. (2007). "A clash of cultures: Cultural differences within American and Japanese animation."

http://citeseerx.ist.psu.edu/viewdoc/download?doi= 10.1.1.619.277\&rep=rep1\&type $=$ pdf

[6] Hayes, T., Edlmann, T.\& Brown, L.(2019). Storytelling: Global Reflections on Narrative

[7] Ridout, C. (2006). Anime Conquers the World. The Australian.

[8] Faiola, A. (2004). We're Playing Their Toons. The Washington Post

[9] McCloud, S. (1994). Understanding comics: The invisible art. New York, NY: HarperCollins.

[10] Schodt, F. (1983). Manga! Manga!: The world of Japanese comics. Tokyo: Kodansha International.

[11] Petersen, R.S. (2011). Comics, manga, and graphic novels: A history of graphic narratives.

[12] Matsutani, M. (1970). Taberareta yamanba [The three little charms]. Illustrated by Y.

[13] Waller, G. (2013). The three magic charms: A kamishibai tale. [video] Last accessed 24th July 2018, https://www.youtube.com/watch?v=O_Ugic0n49 M.

[14] Kasa, N. (2005). Constructing animerica: History, style and spectatorship of anime in the United States. ProQuest Dissertations Publishing.

[15] Joyce, J. (2018). Gunslinging Justice: The American Culture of Violence in Westerns and the Law. Manchester: Manchester UP.

[16] Kohn, A. (2004). Shooters: myths and realities of America's gun cultures. Oxford University Press.

[17] Morillo, S. (1995). Guns and government: A comparative study of European and Japan. Journal of World History, 75-106.

[18] Guns in the United States - Firearms, gun law and gun control. Gun Law and Policy: Firearms and 
armed violence, country by country. Accessed May 19, 2021.

[19] Howard, A., Shudo, K., \& Umeshima, M. (1983). Motivation and values among Japanese and American managers. Personnel Psychology, 36(4), 883-898. https://doi.org/10.1111/j.17446570.1983.tb00517.x

[20] Animelab. (November 25, 2020). Best Order to Watch: Naruto, Shippuden, Boruto Anime Series and Movies. Anime originally created by Masashi Kishimoto. https://www.animelab.com/blog/orderto-watch-naruto-shippuden-boruto-anime-seriesand-movies/

[21] Sakoto Kawasaki. (2020). Storyteller Tora Mihashi Performs at a Kamishibai Event in Tokyo's Arakawa Ward in Early March. The Japan Times.

[22] Madhouse Studio. (1998). Trigun. Hulu. Hulu.com.

[23] Madhouse Studio, Neeraj Chand. (2019). 10 Facts About Trigun that Every Fan Should Know. CBR.com. 